\title{
Additioning alfa fibres in cement mortar
}

\section{Adición de fibras de esparto en mortero de cemento}

\author{
Ernest Bernat-Masoa (Main and Corresponding Author) \\ LITEM Research Group \\ Colom Street 11, TR45 D137, 08222. Terrassa (Spain) \\ ernest.bernat@upc.edu \\ Francesc Puigvertb \\ LITEM Research Group \\ Colom Street 11, TR45 D137, 08222. Terrassa (Spain) \\ francesc.puigvert@upc.edu
}

\section{Hichem Abdelmoulac}

Tunisia Polytechnic School

Rue El Khawarizmi, Site archéologique de Carthage 2078. Tunis (Tunisia)

Hichem.abdelmoula@gowellpetro.com

\section{Lluís Gild}

Strength of Materials and Engineering Structures, Polytechnic University of Catalonia

Colom Street 11, TR45 D123, 08222. Terrassa (Spain)

Iluis.gil@upc.edu

\author{
Manuscript Code: 813 \\ Date of Acceptance/Reception: 14.03.2018/13.09.2016 \\ DOI: 10.7764/RDLC.17.1.72
}

\begin{abstract}
Cement mortar is a broadly used construction material. Adding fibres into the fresh mortar is an effective reinforcing technique to overcome the drawbacks related with the little tensile and flexural strength. Using natural fibres (mostly vegetal) is environmental sustainable and competitive. In particular, alfa fibre, which is produced in Mediterranean area, is herein considered. The main objective of this paper is analysing the mechanical performance of strengthening mortars using alfa fibre. Flexural and compressive tests have been performed and the experimental results showed a significant increase of the flexural strength and the toughness factor, whereas the compressive strength was slightly reduced when adding alfa fibres. The methodology used for measuring the toughness factor has been successfully adapted for this research and, thus, it might be applied to other materials. Different fibre dosages and lengths have been tested and the influence of these parameters have been analysed concluding that adding short fibres is the best option because of the better workability and the greater flexural performance.
\end{abstract}

Key words: Alfa fibre, mortar, strengthening, experimental testing, toughness.

\section{Resumen}

El mortero de cemento es un material ampliamente usado. Añadir fibras en mortero fresco es una manera efectiva de reforzar el material para superponerse a los problemas derivados de su baja resistencia a tracción y flexión. El uso de fibras naturales (mayormente vegetales) es ecológicamente sostenible y competitivo. En particular, se ha considerado para el estudio la fibra de esparto, cuya producción se concentra en áreas de clima mediterráneo. El principal objetivo de este artículo es analizar la mejora de propiedades mecánicas asociada al refuerzo de morteros con fibras de esparto. Ensayos a flexión y compresión se han llevado a cabo y los resultados experimentales muestran un significativo aumento de la resistencia a flexión y el factor de dureza, mientras que la resistencia a compresión se reduce ligeramente al añadir fibras de esparto. La metodología utilizada para medir la tenacidad es una adaptación particular para la presente investigación que resulta de utilidad para el ensayo de otros materiales de características similares. Se han utilizado diferentes dosificaciones de fibra y diferentes longitudes de fibra. La influencia de estos parámetros se ha analizado concluyendo que añadir fibras cortas es la mejor opción, debido al trabajo y resistencia a flexión obtenidos.

Palabras clave: Fibra de esparto, mortero, refuerzo, ensayo experimental, tenacidad.

Cement mortar is one of the most used materials in the construction industry. It is easily mouldable and has a significant compressive strength. However, its range of application is limited by some drawbacks like shrinkage cracking, low tensile strength and what is more restrictive, the brittle failure mode. Adding fibres has been recently studied as a competitive solution to improve the cement mortar's performance. This rising tendency might replace the use of some chemical additives. 
There are hundreds of chemical additions successfully developed to modify the mortar properties in order to improve its mechanical response. Nevertheless, these additions are expensive, show several environmental issues and require some experience to be used correctly under health and safety conditions. In contrast, adding fibres to the fresh mortar is an easy mechanical approach that has been studied as a possible alternative. This approach has been successfully tested in concrete and some concrete codes already consider the possibility of adding natural fibres, for example, $\mathrm{ACl}$ 544.1R (ACl Committee 544, 2008a).

Steel fibres are the most common solution for enhancing the mortar and concrete tensile strength. In fact, several codes consider their application and provide guidelines for taking into account their mechanical contribution to the mortar strength. It is the case of the American ACI 544.4R (ACl Committee 544, 2008b) and the Spanish EHE-08 (Ministerio de Fomento. Comisión Permanente del Hormigón, 2008). The cost and environmental sustainability of producing steel or plastics fibres (Pereira de Oliveira \& Castro-Gomes, 2011) are the main disadvantages of these fibres in front of using natural ones. The current tendency of considering natural fibres is based on their environmental advantages: low energy consumption for their production, low $\mathrm{CO}_{2}$ emissions or even $\mathrm{CO}_{2}$ absorption and being a renewable resource with no toxicity are some of the strong points of the natural fibres as Corberos-Rodríguez (Corberos-Rodriguez, 2009) pointed out. Because of this, using vegetal fibres might be a sustainable alternative to the plastic ones.

Using natural fibres might be thought as a general practice, but in order to reduce the transportation costs, using local natural fibres is the most efficient option. Based on this purpose, the present work uses alfa fibre. The production of alfa fibre (stipa tenacissima) is cheap, easy and provides a new use for this abundant resource in the Mediterranean area (north of Africa and south of Spain). It is a reasonable alternative to the currently most used natural fibres in construction: bamboo, jute, hemp - see the commercial solution of hempcrete by Hempcrete Pty. (Hempcrete Pty. Ltd., n.d.) - or sisal, which has even been tested in composite materials with resin matrix (Li, Mai, \& Ye, 2006).

In most of the cases, the research about using natural fibres for strengthening mortar or concrete is restricted to the analysis of the durability, which is a critical aspect. This has been studied for several researches. The works of Tol et al. (Toledo Filho, Scrivener, England, \& Ghavami, 2000) and Ramakrishna and Sundararajan (Ramakrishna \& Sundararajan, 2005) are examples of investigations which studied the influence of the diameter, humidity or chemical composition of the fibres on the performance of the resulting composite material. The research in (Ramakrishna \& Sundararajan, 2005) has to be highlighted for the comprehensive work at summarising and comparing the results of other researches in the field of the durability of the natural fibres. In contrast, little research regarding the mechanical performance of mortar strengthened with natural fibres has been found in the literature review. Among the most significant investigations, the work of Toledo et al. (Toledo Filho, Ghavami, Sanjuán, \& England, 2005) stands out because of the inclusive study about the shrinkage and creeping of the cement mortar composite materials. One of the few researches about the flexural strength and toughness assessment of cement mortar strengthened with natural fibres is the work of Juárez-Alvarado et al. (Juárez-Alvarado, Villarreal, \& Rechy-de-Von-Roth, 2004) about using sisal fibres.

Although there are numerous advantages of strengthening mortar or concrete with natural fibres, its use in infrastructures construction industry or civil engineering applications is still controversial. Dittenber and GangaRao (Dittenber \& GangaRao, 2012) presented an interesting review about the usage of natural fibre in composites for construction purposes.

Although the presented advantages, there are still several doubts around the mechanical response of the mortar and concrete strengthened with natural fibres. Because of this, it might be concluded that further research on this topic is needed. The long-term commercial objective might be using this material for producing pavements or facade panels which require some tensile strength and ductility. Hence, the specific aim of this paper is to present experimental evidences of the performance of alfa fibre strengthened mortar which could be used as a base for further developments. Experimental tests have been carried out to characterise the compressive and flexural response of this composite material. The flexural tests have been developed as modified standard tests and, thus, might be applicable for many other materials with lower Young's modulus than mortar or concrete. The influence of the length and the dosage of fibres have been studied. Finally, a significant flexural ductility increase has been proved.

\section{Materials and methods}

Two materials were used in the current research: Portland mortar and alfa fibres. Alfa fibres were industrially dried, submerged in chemical solutions of $\mathrm{NaOH}$ and $\mathrm{NaClO}$, and dried again to finally produce an alfa fibre tow which is presented in a roll. This is the typical procedure used to obtain commercially available alfa fibres. Only the diameter of the tow, $d=0.17 \mathrm{~mm}(\mathrm{CoV}=11.3 \%)$, was experimentally obtained as an average of 20 measurements using a digital 
calliper. The theoretical tensile strength of the alfa fibre, $f_{t f}$, is around $250 \mathrm{MPa}$ according with bibliography, see the work of Paiva et al. (Paiva, Ammar, Campos, Cheikh, \& Cunha, 2007), and the Young's modulus is nearby 15 GPa according with the research carried out by Arrakhiz et al. (Arrakhiz, Malha, Bouhfid, Benmoussa, \& Qaiss, 2012). However, these values are only introduced to describe the general material and can be affected by the production procedure. Although the natural origin of the fibres makes their characteristics heterogeneous and variable, the tensile strength and Young's modulus of the fibres were not investigated for the specific fibres used because it was not expect to reach their maximum tensile strength. In addition, adherence issues were expected in the fibre-mortar interface, which make the Young's modulus of fibres of little relevance for the research. The experimental observations have confirmed this initial hypothesis, as presented in section 0 .

Regarding the mortar, only one type was considered. Its main properties were: compression strength, $f_{c m}=24.7 \mathrm{MPa}$ and flexural strength, $f_{x m}=8.1 \mathrm{MPa}$. These properties were experimentally obtained with 12 tests for the compression strength and 24 for the flexural strength at 28 days and with standardised specimens: $40 \times 40 \times 160 \mathrm{~mm}^{3}$ for flexural strength and 40mm cubes for compression, according with EN 1015-11:2000 (Committee AEN/CTN 83, 2007). The mortar was classified as R3 type. Thus, the Young's modulus should be greater than 15GPa. This mortar is distributed as a grey powder in $25 \mathrm{~kg}$ bags.

\section{Specimens production}

Two different types of tests were conducted to characterise the mechanical response of the alfa fibre strengthened mortar. The first one, oriented to obtain the compression response, was performed on cubic specimens (100x100x100 $\mathrm{mm}^{3}$ ) according with UNE-EN 12190:1999 (Committee AEN/CTN 83 B/517, 1999), whereas the second one, which was intended to determine the flexural response of this composite material, used parallelepiped specimens (100x100x350 $\mathrm{mm}^{3}$ ) as suggested the Japanese standard JSCE-SF4 (JSCE-SF4, 1984).

Three different fibre dosages have been considered for studying the flexural response and two for the compression tests. It has to be remarked that the dosage is the dry weight of the alfa fibre to be added over the volume of the casted specimen. In both cases, four maximum fibre lengths have been used. The fibre dosages and lengths for each specimen are summarized in Table 1 and Table 2. Three cubic specimens and three flexion specimens with no fibres have been also produced and tested for comparison reference.

Table 1. Number of compression specimens with alfa fibre. Self-Elaboration.
\begin{tabular}{lccccc} 
& \multicolumn{4}{c}{ Fibre length $(\mathrm{mm})$} \\
Dosage $\left(\mathrm{kg} / \mathrm{m}^{3}\right)$ & 10 & 25 & 50 & 75 \\
\hline 2.5 & 3 & 3 & 3 & 3 \\
10 & 3 & 3 & 3 & 3 \\
\hline
\end{tabular}

Table 2. Number of flexural specimens with alfa fibre. Self-Elaboration
\begin{tabular}{lcccc}
\multicolumn{5}{c}{ Fibre length $(\mathrm{mm})$} \\
Dosage $\left(\mathrm{kg} / \mathrm{m}^{3}\right)$ & 10 & 25 & 50 & 75 \\
\hline 2.5 & 3 & 3 & 3 & 4 \\
5 & 3 & 3 & 3 & 3 \\
10 & 3 & 3 & 2 & 2 \\
\hline
\end{tabular}

The production of the specimens has consisted of mixing the dry mortar with water where the alfa fibres had been previously added. The mix has been casted in appropriate moulds. With more detail, the procedure has been:

a) Cutting the alfa fibre tow to the corresponding maximum length of the fibres: 10, 25, 50 or $75 \mathrm{~mm}$. These are maximum values of the length of fibres used in each addition because the cutting process assured the maximum dimension but shorter fibres might be included between two cutting points. Thus, the average length of the fibres is not measured but the maximum one cut from a continuous roll is imposed. Common scissors were used to cut the fibres.

b) Weighting the fibres to be added in one mixing batch depending on the corresponding dosage $(2.5,5$ or 10 $\mathrm{kg} / \mathrm{m}^{3}$ ), the type of specimen (compression or bending test) and the number of specimens to be cast.

c) Wetting the alfa fibres during 24 hours immersing them in water. The purpose of this step is to saturate the fibres to assure they would not absorb water from the mortar matrix. This action is aimed to avoid the lack of water in the mixture due to the water absorption of the dry fibres. 
d) Superficially drying the fibres (leaving them out of the water for $10 \mathrm{~min}$ ) to prevent them from bringing extra water to the mixture with the mortar.

e) Measuring the recommended amount of water corresponding with the quantity of mortar to be mixed. The fresh mortar with alfa fibres weights $24 \mathrm{kN} / \mathrm{m}^{3}$ and the water proportion has been set to be $13 \%$ of the total weight.

f) Putting the measured water and the prepared fibres into the mixing recipient. Adding the mortar powder while mixing with a mechanical mixer. The mixing continued until a uniform paste is obtained and the fibres are uniformly distributed in the mix.

g) Casting the specimens and compacting the mixture with vibration movements and applying pressure. The mixture has been placed in layers of $3 \mathrm{~cm}$ of maximum thickness and vibrated after casting each layer up to fulfil the mould.

h) Curing the specimens in environmental indoors conditions for 21 days before testing them. The specimens have been unmoulded approximately 14 days after casting the mix.

Some drawbacks have been observed during the preparation of the specimens. Firstly, it is worth referring to the fact that longer fibres tangled around the mixing machine making it very difficult to achieve a uniform distribution of fibres in the mix. A manual mixing has been proposed and used for these cases. The other problem which is important to be highlighted is the large amount of energy required to compact the fibre-strengthened mortar in comparison with the fresh mortar with no fibres. This qualitative observation arises from the experimental experience of the people who casted the specimens. In addition, it has been confirmed with the measurement of consistency, which has been performed according to European standard EN 1015-3 (Committee AEN/CTN 83, 2000), and resulted with consistency values around $220 \mathrm{~mm}$ for unreinforced mortar and lower than $120 \mathrm{~mm}$ for all cases with fibres.

\section{Test setup and procedure}

Two different series of tests were conducted. The compression tests had the main objective of obtaining the maximum compressive strength for each combination of alfa dosage and length. The flexural tests were intended to find the material toughness following the recommendations of the Japanese standard JSCE-SF4 (JSCE-SF4, 1984).

The compression test setup was composed by a hydraulic jack (1000 kN range) and a steel plate ( $20 \mathrm{~mm}$ thickness) placed on the jack to distribute the force along the lower contact face of the specimen which was laid on this plate. Over the specimen another steel plate $(20 \mathrm{~mm}$ thickness) was placed to uniform the contact with the specimen. When the jack was activated all the parts moved upwards until the contact with a fixed reaction steel plate (60 mm thickness). From this point and on the specimen was compressed. The test began when the contact with the reaction plate was reached.

The compression test consisted of:

a) Installing either two or four concrete strain gages of $120 \Omega$ depending on the specimen. These were $60 \mathrm{~mm}$ long and $10 \mathrm{~mm}$ width. The specimens with two strain gages (sixteen specimens, two of each kind) had one sensor oriented with the force direction to measure the compression strain. The other one was installed perpendicular to the force direction in order to measure the lateral strains. The specimens with four strain gages (eight specimens, one for each length and dosage combination) had two gages installed in each mentioned direction. The strain gages position as well as the test configuration is shown in the sketch of

b) Figure 1 (left). All strain gages were centred in the corresponding face of the sample.

Figure 1. Test configurations for determining the compressive strength (left) and the flexural strength and toughness (right). Self-Elaboration.
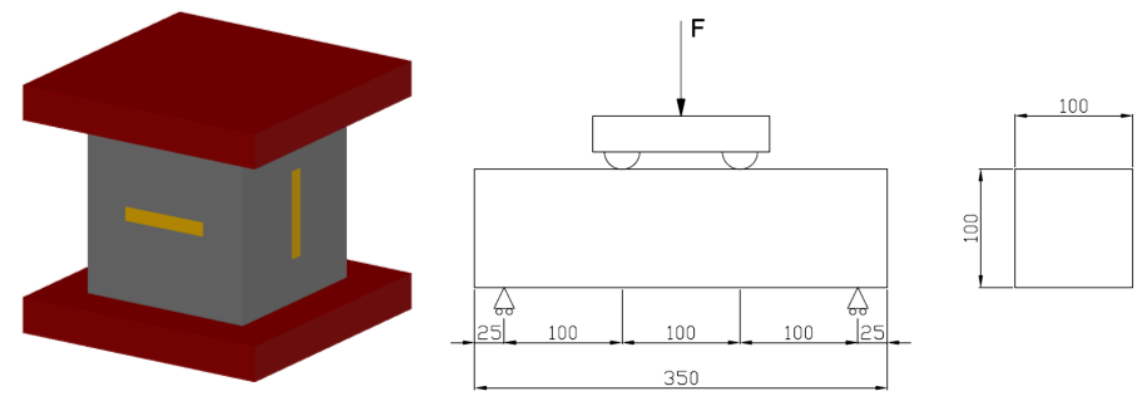

c) Placing the specimen in the test position, centring the specimen in the compression plates.

d) Connecting the strain gages to the acquisition hardware. 
e) Initialising the data recording at $50 \mathrm{~Hz}$ and beginning the load application. The load was simultaneously recorded with the strain measurements. The oil pressure at the jack entry was the indirect measurement of the applied load.

f) The test finished with the compressive collapse of the specimen.

A four points bending test was set up for determining the flexural strength and toughness of the flexural specimens. The specimens laid on two simple supports (steel rods) and the load was applied with an electromechanic press ( $50 \mathrm{kN}$ range) which had a loading tool connected. This element contacted the specimen with two little rods which transmitted the force. The distance between supports was $300 \mathrm{~mm}$ and the distance between load application lines was $100 \mathrm{~mm}$.

Figure 1 (right) shows a sketch of the test set up.

The flexural test, which might be applied with little modifications to other materials, consisted of:
a) Placing the specimen in the test position, centred and aligned with the loading tool.
b) Installing two linear displacement potentiometers to measure the deflection at mid-span. Connecting these sensors to the acquisition hardware and descending the loading tool until contact.
c) Initialising the data recording and beginning the test by descending the loading tool (which was in contact with the specimen at its thirds) at $0.1 \mathrm{~mm} / \mathrm{min}$ as suggested in the Japanese standard JSCE-SF $4{ }^{17}$.
d) The test finished when the loading machine descended $2 \mathrm{~mm}$ after reaching the maximum load.

\section{Compressive strength tests}

Twenty-seven tests on cubic specimens have been performed to obtain the compressive strength for each fibre dosage and each maximum length. All these specimens failed by developing vertical cracks. These cracks opened and the process resulted in the mortar crushing. Qualitatively, large lateral deformation is observed in most of the cases. The compressive strength, which is calculated by assuming a uniform load distribution, is presented in Table 3. It is observed that adding fibres does not contribute to enhance the compressive response of the mortar but the contrary, in some cases there is a compressive strength reduction associated with the alfa fibre addition.

Table 3. Results of the compressive strength tests on cubic specimens (MPa). Self-Elaboration.

\begin{tabular}{lccccc}
\hline \multicolumn{2}{c}{ Compressive strength (MPa) } & & & & \\
\cline { 1 - 4 } Dosage $\left(\mathrm{kg} / \mathrm{m}^{3}\right)$ & Maximum length $(\mathrm{mm})$ & Specimen 1 & Specimen 2 & Specimen 3 & Average \\
\hline 0 & --- & 10.4 & 15.0 & 12.8 & 12.7 \\
2.5 & 10 & 11.5 & 11.6 & 10.4 & 11.2 \\
& 25 & 16.4 & 16.4 & 13.2 & 15.3 \\
& 50 & 9.8 & 10.6 & 12.7 & 11.0 \\
& 75 & 15.0 & 11.6 & 12.2 & 12.9 \\
10 & 10 & 12.1 & 9.6 & 11.3 & 11.0 \\
& 25 & 12.4 & 13.7 & 7.6 & 11.2 \\
& 50 & 11.7 & 9.8 & 12.0 & 11.2 \\
& 75 & 9.9 & 13.9 & 12.4 & 12.0 \\
\hline
\end{tabular}

Analysing the strain measurements, it is noticed that the lateral strain is even larger, in absolute value, than the vertical strain for most of the cases. In addition, the lateral strain increases earlier for the cases with more fibres $\left(10 \mathrm{~kg} / \mathrm{m}^{3}\right)$. This fact points out there is a relationship between the amount of fibre included into the mortar and the lateral deformation response of the specimens.

Moreover, it has to be mentioned that the measurements of the strain gages are heterogeneous. Due to the complex response of the fibre reinforced mortar, a significant scattering is obtained. For example, depending on the cracking pattern some strain gages could have been under tensile efforts although they were supposed to work in compression. This effect is more common for the specimens with more fibres. 


\section{Bending tests}

Thirty-eight specimens have been tested in flexion to obtain the flexural strength of the fibre-reinforced mortar for each dosage and maximum length of the fibres. The flexural strength is calculated by assuming a linear stress distribution along the specimen's section. The obtained results of the flexural strength are presented in Table 4, where the last row of data for each dosage corresponds to the average results of the repeated tests. It is observed that there is a relationship between using fibres and the increase of the flexural strength: Using greater amounts of fibres tends to increase the flexural strength whereas using shorter fibres also contributes to improve this mechanical property. On the whole, the greater flexural strength increase corresponds with the specimens which included the shortest fibres (10 $\mathrm{mm}$ ). For most of the cases, adding fibres contribute to enhance the flexural performance in comparison with plain mortar. Only seven of the thirty-five tests on specimens strengthened with fibres resulted in lower flexural strength values. Four of these correspond with the minor fibre dosage $\left(2.5 \mathrm{~kg} / \mathrm{m}^{3}\right)$ and the rest are associated with the longest fibres (50 and $75 \mathrm{~mm}$ ).

\begin{tabular}{|c|c|c|c|c|}
\hline \multirow{2}{*}{$\begin{array}{l}\text { Flexural strength }(\mathrm{MPa}) \\
\text { Fibres dosage }\left(\mathrm{Kg} / \mathrm{m}^{3}\right)\end{array}$} & \multicolumn{4}{|c|}{ Maximum fibre length $(\mathrm{mm})$} \\
\hline & 10 & 25 & 50 & 75 \\
\hline \multirow[t]{5}{*}{2.5} & 1.620 & 0.568 & 1.480 & 1.066 \\
\hline & 1.420 & 1.295 & 0.580 & 1.206 \\
\hline & 1.437 & 0.750 & 0.818 & 1.700 \\
\hline & & & & 1.340 \\
\hline & 1.492 & 0.871 & 0.959 & 1.328 \\
\hline \multirow[t]{4}{*}{5} & 1.656 & 1.302 & 0.914 & 1.192 \\
\hline & 1.732 & 1.001 & 0.834 & 0.608 \\
\hline & 1.362 & 0.963 & 1.835 & 2.376 \\
\hline & 1.583 & 1.089 & 1.195 & 1.392 \\
\hline \multirow[t]{4}{*}{10} & 1.550 & 1.216 & 1.373 & 0.850 \\
\hline & 2.063 & 1.782 & 1.602 & 1.633 \\
\hline & 2.017 & 1.132 & & \\
\hline & 1.877 & 1.376 & 1.487 & 1.241 \\
\hline \multirow[t]{4}{*}{0} & \multicolumn{4}{|c|}{0.539} \\
\hline & \multicolumn{4}{|c|}{0.794} \\
\hline & \multicolumn{4}{|c|}{1.343} \\
\hline & \multicolumn{4}{|c|}{0.892} \\
\hline
\end{tabular}

In addition, the toughness of each specimen has been calculated. This parameter is related with the energy dissipation corresponding with the growing process of the flexural cracks. The toughness is calculated as the area under the forcedeflection curve up to a deflection of $\delta_{\mathrm{L} / 150}=2 \mathrm{~mm}$ at mid-span and it is measured in $\mathrm{N} \cdot \mathrm{mm}$. The toughness factor, $\sigma_{t}$, which measures the contribution of the fibres, is calculated according with Eq.1. $B, H$ and $L$ are the width, height and free span of the specimen respectively.

$$
\sigma_{t}(M P a)=\text { Toughness }(N \cdot m m) \cdot \frac{L(m m)}{B(m m) \cdot H^{2}\left(m m^{2}\right) \cdot \delta_{\frac{L}{150}}(m m)}
$$

These calculation procedures are proposed, for fibre-reinforced concrete, in the Japanese code by JSCE (JSCE-SF4, 1984). The obtained results of the toughness factor are shown in Table 5, where the last row of data for each dosage corresponds to the average results of the repeated tests.

Moreover, it has to be mentioned that all specimens failed due to bending. One crack at mid-span was observed in all bending tests (see Figure 2). This crack always began at the tensile side of the specimen (bottom). The specimens with no fibres were divided in two parts when the maximum load was reached whereas the fibres kept the two parts united for most of the cases which included fibres (see Figure 3). 


\begin{tabular}{|c|c|c|c|c|}
\hline \multirow{2}{*}{$\begin{array}{l}\text { Toughness factor (MPa) } \\
\text { Fibres dosage }\left(\mathrm{Kg} / \mathrm{m}^{3}\right)\end{array}$} & \multicolumn{4}{|c|}{ Maximum fibre length (mm) } \\
\hline & 10 & 25 & 50 & 75 \\
\hline \multirow[t]{5}{*}{2.5} & 0.641 & 0.210 & 0.335 & 0.467 \\
\hline & 0.595 & 0.270 & 0.191 & 0.478 \\
\hline & 0.560 & 0.250 & 0.167 & 0.493 \\
\hline & & & & 1.058 \\
\hline & 0.599 & 0.243 & 0.231 & 0.624 \\
\hline \multirow[t]{4}{*}{5} & 0.834 & 0.732 & 0.455 & 0.476 \\
\hline & 0.785 & 0.468 & 0.202 & 0.279 \\
\hline & 0.483 & 0.441 & 1.098 & 1.045 \\
\hline & 0.700 & 0.547 & 0.585 & 0.600 \\
\hline \multirow[t]{4}{*}{10} & 0.592 & 0.412 & 0.594 & 0.410 \\
\hline & 0.675 & 0.916 & 0.687 & 0.558 \\
\hline & 1.285 & 0.469 & & \\
\hline & 0.851 & 0.599 & 0.640 & 0.484 \\
\hline \multirow[t]{4}{*}{0} & \multicolumn{4}{|c|}{0.141} \\
\hline & \multicolumn{4}{|c|}{0.201} \\
\hline & \multicolumn{4}{|c|}{0.443} \\
\hline & \multicolumn{4}{|c|}{0.261} \\
\hline
\end{tabular}

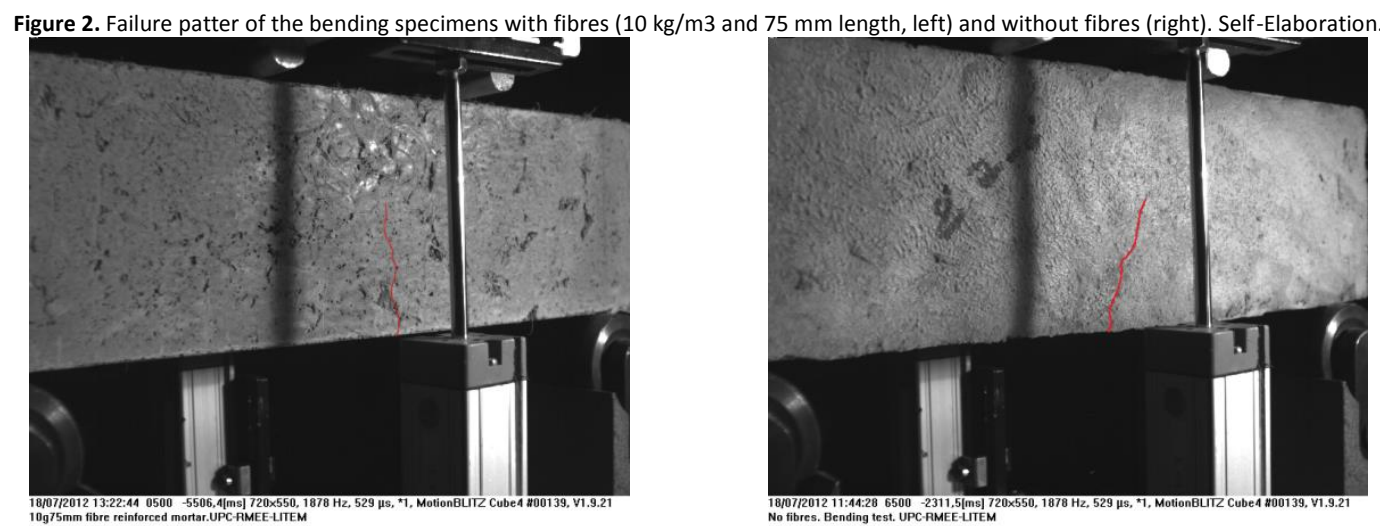

Figure 3. Two parts of the specimen which have been kept united by the fibres after the bending test. Self-Elaboration.

The response of the tested specimens is shown in Figure 4, Figure 5, and Figure 7. It is noticed that the most repeatable tests correspond, in general, with the cases with the shorter fibres: $10 \mathrm{~mm}$ (see Figure 4 and Figure 6). Qualitatively, the force-deflection response is analogue for all tested cases. There is an initial linear response up to the maximum load when the specimen cracks. After this maximum load, there is a residual strength, which depends on the amount of fibres and their length. 

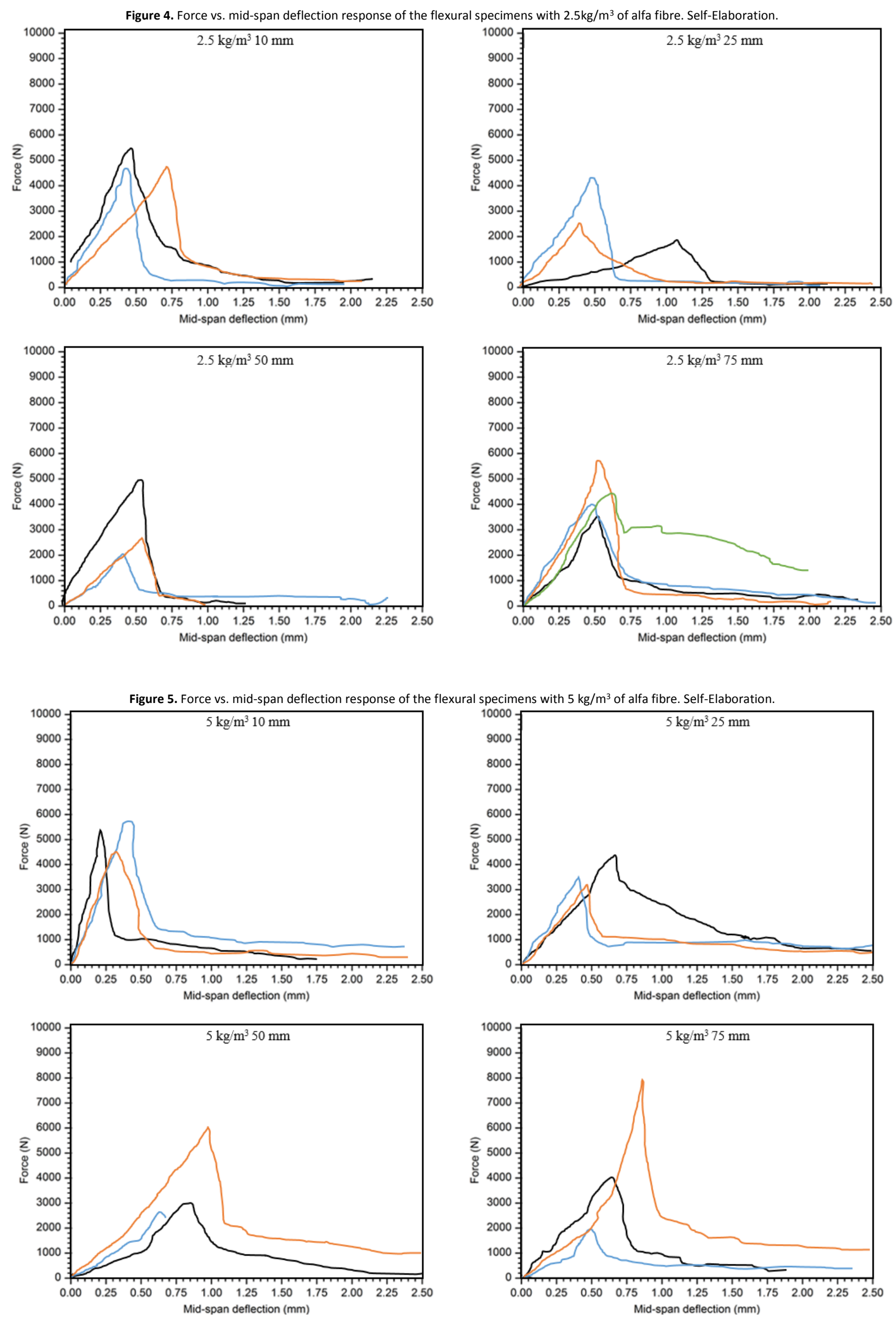

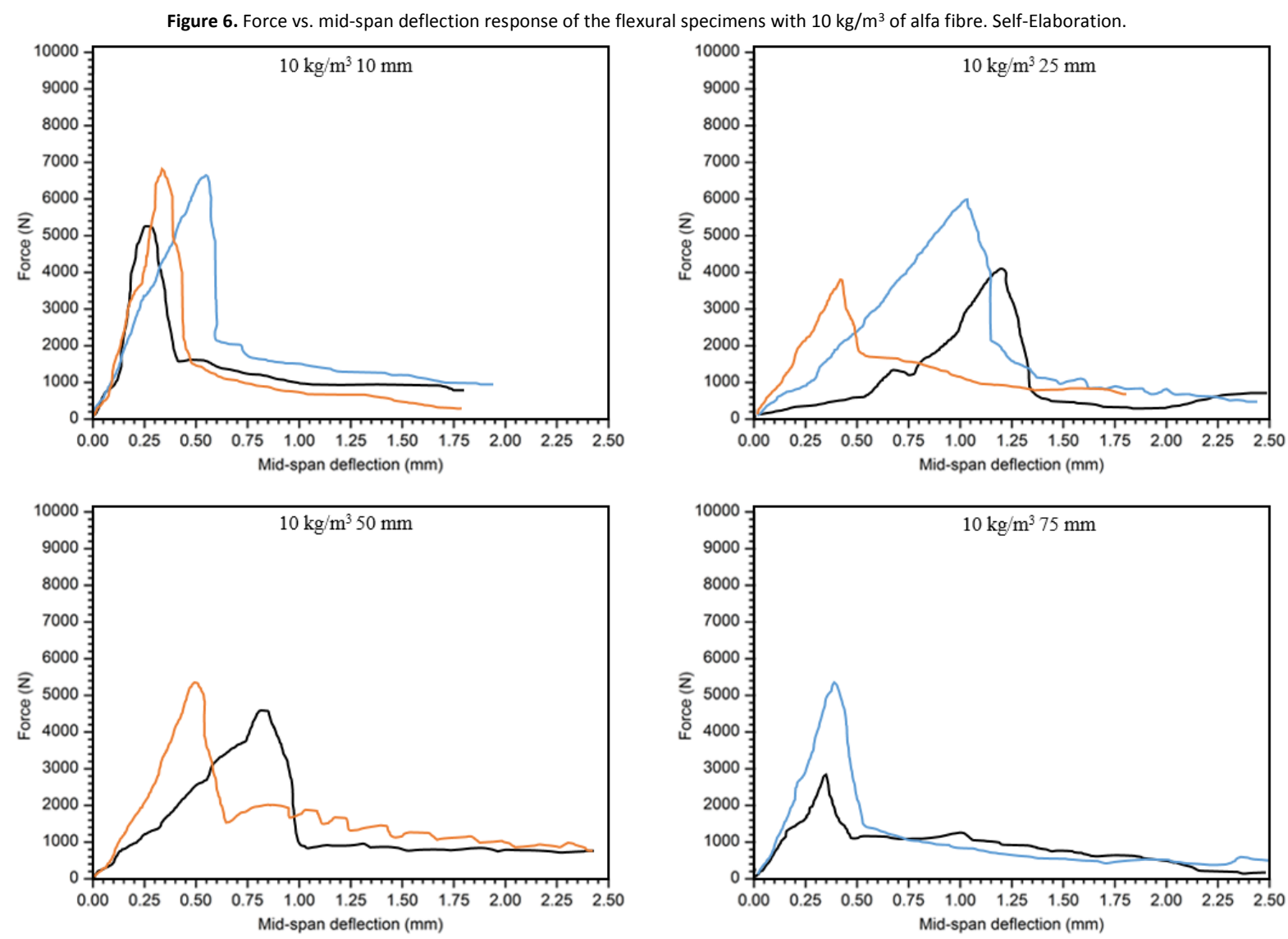

Figure 7. Force vs. mid-span deflection response of the flexural specimens with no fibres. Self-Elaboration.

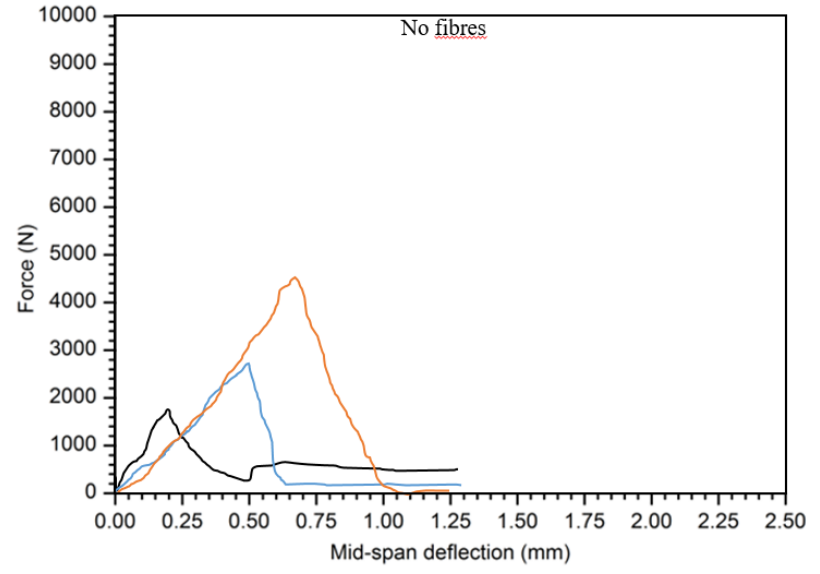

Discussion

Comparative graphs are presented in Figure 8, Figure 9 and Figure 10 in order to analyse the influence of the fibre dosage and the maximum fibre length on the compressive strength, the flexural strength and the toughness factor respectively. The variation of these parameters, which is plotted in the mentioned graphs, is relative to the average values obtained from the tests on the specimens with no fibres included.

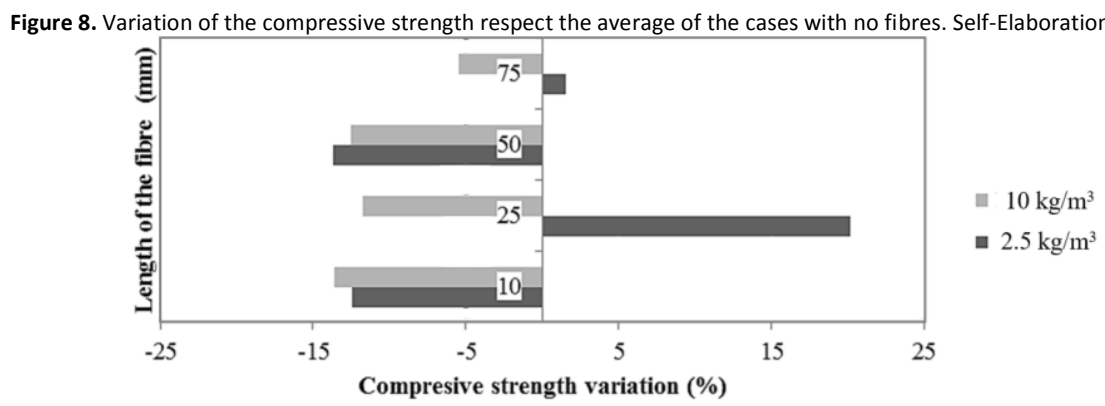


Figure 9. Variation of the flexural strength respect the average of the cases with no fibres. Self-Elaboration.
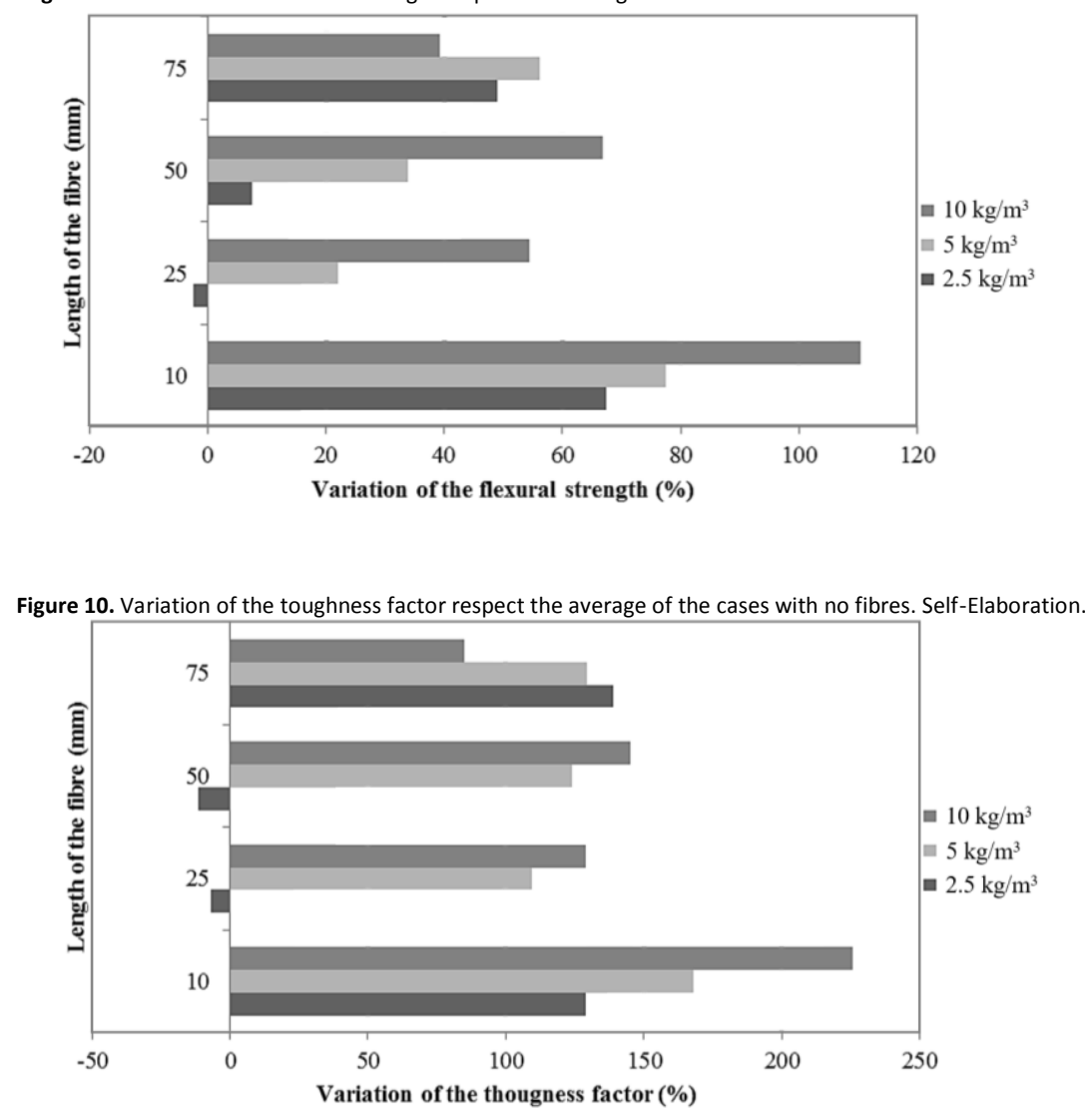

Regarding the compressive strength (see Figure 8), it is worth noticing that adding alfa fibres resulted in a reduction of the compressive strength for most of the cases tested. This fact might be related with the major number of voids which were qualitatively appreciable in the specimens that included fibres. The complexity of mixing the fibres, the difficulties encountered to get them uniformly distributed in the mortar and the requirement of extra energy to compact the mortar with fibres seem to be the most plausible justifications for the compressive strength reduction. Although the measured data were not enough to obtain a clear tendency of the compressive response, the strength decrease was always less than $15 \%$ of the compressive strength of the mortar with no fibres. In fact, in the case of a fibre dosage of $2.5 \mathrm{~kg} / \mathrm{m}^{3}$ and a maximum fibre length of $25 \mathrm{~mm}$, the compressive strength is greater than the reference specimens with no fibres. In this case the fibres were long enough to assure the adherence with the mortar but short enough to prevent the mixing problems for this specific dosage. In addition, Figure 8 shows that the specimens with less fibre $\left(2.5 \mathrm{~kg} / \mathrm{m}^{3}\right)$ are the ones with best compressive performance except for the case of adding fibres with a maximum length of $50 \mathrm{~mm}$ in which case the obtained results are very similar for both dosages 2.5 and $10 \mathrm{~kg} / \mathrm{m}^{3}$.

The presence of fibres punctually concentrated inside the specimens due to the mixing problems might also explain the scattered response of the compressive tests discussed before. The presence of a large amount of fibres near the surface might contribute to the observed tensile response of the surfaces of the cubic specimens. The fibres tend to expand laterally when compressed causing the measured tensile strains even in the vertical strain gages for relative low applied forces. This fact might suggest that the Young's modulus of the mortar strengthened with alfa fibre might be significantly lower than the Young's modulus of the mortar. Nevertheless, additional experimental tests would be necessary to confirm this new hypothesis.

Focusing on analysing the results of the flexural tests, it is worth mentioning that the presence of the fibres contributes to reduce the propagation of the cracks and their thicknesses. It might be due to the "sewing" effect of the fibres which tend to maintain both sides of a crack united. In this process, the mortar-fibre adherence and the tensile strength of the fibre are both important. It has to be highlighted that alfa fibres work as a passive reinforcement, so the cracks have to be developed before the fibres are tensioned.

As it is shown in Figure 9, the flexural strength is significantly influenced by the fibre dosage for the fibre lengths of 10 , 25 and $50 \mathrm{~mm}$. Increasing the amount of fibres has caused an increase of the flexural strength for these three maximum fibre lengths. However, increasing the fibre dosage from 5 to $10 \mathrm{~kg} / \mathrm{m}^{3}$ for the cases with longest fibres $(75 \mathrm{~mm})$ has 
caused a decrease of the flexural strength. This loss of strength for the longest fibres might be related with the mixing problems and the inhomogeneous final composition.

The influence of the fibre length is also remarkable. The short fibres (maximum length of 10mm) achieve the greatest flexural strength. This significant performance might be explained by the easy use of these fibres, which can be easily introduced in the mix and homogeneously distributed. The minimum flexural strength for the dosages of 2.5 and 5 $\mathrm{kg} / \mathrm{m}^{3}$ is observed for the maximum fibre length of $25 \mathrm{~mm}$. The anchorage length of these fibres was still reduced but the size was long enough to cause some mixing problems. Hence, $25 \mathrm{~mm}$ seems to be the length of the alfa fibre associated with the poorest performance in bending. For dosages of 2.5 and $5 \mathrm{~kg} / \mathrm{m}^{3}$ and maximum fibre lengths of 25 mm or longer ( 50 and $75 \mathrm{~mm}$ ) it is observed that increasing the fibre length contributes to enhance the flexural strength. This result might be related with the longer anchorage length of the added fibres. It is significant that the relatively lower dosages $\left(2.5\right.$ and $5 \mathrm{~kg} / \mathrm{m}^{3}$ ) allow increasing the length of the fibres without causing mixing problems. In contrast, the lower flexural performance for a dosage of $10 \mathrm{~kg} / \mathrm{m}^{3}$ is obtained for a maximum length of $75 \mathrm{~mm}$. For this amount of fibres $\left(10 \mathrm{~kg} / \mathrm{m}^{3}\right)$, which was already difficult to obtain the homogeneous mixing, increasing the fibre length can only cause more fibre tangling around the mixing machine and thus, be associated with lower flexural strength.

The dependence of toughness factor on the fibre length and dosage (see Figure 10 and Table 5) is similar to the dependence described for the flexural strength. For the largest amounts of fibre $\left(5\right.$ and $\left.10 \mathrm{~kg} / \mathrm{m}^{3}\right)$ the shortest fibres $(10 \mathrm{~mm})$ achieve the best performance because there are less mixing problems. In contrast, the cases with less added fibre $\left(2.5 \mathrm{~kg} / \mathrm{m}^{3}\right)$ achieve a larger value of the toughness factor for the longest fibres $(75 \mathrm{~mm})$. It is worth remarking that the fibre lengths of 25 and $50 \mathrm{~mm}$ achieve the minimum flexural strength for the case of the minimum fibre amount $\left(2.5 \mathrm{~kg} / \mathrm{m}^{3}\right)$. This fact might be explained because these lengths cause mixing problems but do not develop enough anchorage length to compensate this effect as the $75 \mathrm{~mm}$ long fibres do.

All cases using a dosage of $5 \mathrm{~kg} / \mathrm{m}^{3}$ or higher of alfa fibre result in an increase of the toughness factor over $75 \%$, which means more energy dissipation to open the cracks.

Taking into account the compressive and flexural results altogether it seems that the increase of the flexural performance associated with using alfa fibres at strengthening mortar might justify the compressive strength reduction if the application case allows this possibility. In addition, the cases with low dosages correctly work with long fibres, whereas the larger dosages require using shorter fibres. Nevertheless, using $10 \mathrm{~mm}$ long fibres brings a significant flexural increase for all dosages. Thus, it might be recommendable using short (around $10 \mathrm{~mm}$ ) alfa fibres at reinforcing cement mortar.

Finishing with the discussion, it has to be mentioned that observation of the tested specimens proved that fibres slid inside mortar matrix instead of breaking. Thus, pull-out mechanism controlled the mechanical response in both tests and for all dosages and adherence tests are proposed for future researches with mesoscale approach. Figure 3 supports this fact: fibres are not broken but they have slid from their initial position allowing the separation of the two halves of a flexural tested sample.

Finally, fibre distribution issues were observed for the cases with longer fibres and greatest volumes because of their tendency to tangle. This was not observed for the cases with shortest fibres $(10 \mathrm{~mm})$ which were uniformly distributed.

An experimental campaign to characterise the influence of the fibre length and the fibre dosage on the compressive and flexural strength of the cement mortar with alfa fibre has been presented. Twenty-seven compression tests and thirty-eight flexural tests, considering three different fibre dosages and four different fibre lengths have been performed and are herein presented.

The main conclusion is that the flexural strength of a commercial Portland cement mortar might be increased by adding alfa fibres. In addition, the corresponding toughness factor would also be increased, which means that more energy would be required to open the cracks in flexion. However, adding alfa fibres seems related with a slight decrease of the compressive strength.

The particular conclusions of this research are:

- The best flexural toughness is obtained for two combinations: the minimum dosage of the longest fibres and the maximum dosage of the shortest fibres. 
- Considering the production procedure and the obtained results, it is suggested to use a maximum length of 10 $\mathrm{mm}$ when adding alfa fibres to the used particular fresh mortar.

- Adding $5 \mathrm{~kg} / \mathrm{m}^{3}$ or more of alfa fibre causes mixing problems with the considered Portland mortar and requires extra energy to compact the mortar into the moulds.

- The length of the fibres might contribute to the adherence between fibres and mortar. It is indirectly deduced from the analysis of the overall results but fibre-mortar adherence tests were necessary to confirm this point. Nevertheless, mixing and compaction issues have been observed for lengths larger than $10 \mathrm{~mm}$.

- The presence of fibres increases the lateral deformation of the compressed specimens, which shows a remarkable lateral deformation and a reduction of the compressive strength always under the threshold value of $15 \%$.

- The proposed experimental techniques might be applicable for other fibre-reinforced materials than cement. Thus, the presented methodology is exportable to other solid materials, whose cracking energy dissipation should be measured

Further experimental research is required to characterise comprehensively the compressive, tensile and flexural response of the alfa-reinforced Portland mortar. In particular, community is encouraged to extend the flexural tests presented herein but following EN 14651:2005 standard (CTN 127, 2007) for wider comparative results. In addition, extra tests are necessary to obtain the constitutive model of the contact between the fibres and the mortar. Finally, it has been observed that adding alfa fibres might reduce the Young's modulus of the resulting strengthened mortar in comparison with the mortar without fibres. Thus, further research is required to confirm this hypothesis too.

\section{References}

ACI Committee 544. (2008a). ACI 544.1R-96 Report on Fiber Reinforced Concrete. Farmington Hills: American Concrete Institute.

ACI Committee 544. (2008b). ACI 544.4R-88 Design Considerations for Steel Fiber Reinforced Concrete. Farmington Hills: American Concrete Insitute.

Arrakhiz, F. Z., Malha, M., Bouhfid, R., Benmoussa, K., \& Qaiss, A. (2012). Tensile, flexural and torsional properties of chemically treated alfa, coir and bagasse reinforced polypropylene. Composites Part B: Engineering, 1-7. https://doi.org/10.1016/j.compositesb.2012.10.046

Committee AEN/CTN 83. (2000). UNE-EN 1015-3:2000. Métodos de ensayo para morteros de albañilería. Parte 3: Determinación de la consistencia del mortero fresco (por la mesa de sacudidas). Madrid: AENOR.

Committee AEN/CTN 83. (2007). UNE-EN 1015-11:2000/A1:2007. Métodos de ensayo de los morteros para albañilería. Parte 11: Determinación de la resistencia a flexión y a compresión del mortero endurecido. Madrid: AENOR.

Committee AEN/CTN 83 B/517. (1999). BS EN 12190. Products and systems for the protection and repair of concrete structures. Test methods. Determination of compressive strength of repair mortar. UK: BSI.

Corberos-Rodriguez, C. (2009). Uso de fibras vegetales procedentes de explotaciones agricolas en la edificación sostenible. Tesina, Universidad Politécnica de Cataluña, Escuela Técnica Superior de Arquitectura de Barcelona, Departamento de Construcciones Arquitectónicas.

CTN 127. (2007). UNE-EN 14651:2007. Método de ensayo para hormigón con fibras metálicas. Determinación de la resistencia a la tracción por flexión (límite de proporcionalidad (LOP), resistencia residual). Madrid: AENOR.

Dittenber, D. B., \& GangaRao, H. V. S. (2012). Critical review of recent publications on use of natural composites in infrastructure. Composites Part $A$ : Applied Science and Manufacturing, 43(8), 1419-1429. https://doi.org/10.1016/j.compositesa.2011.11.019

Hempcrete Pty. Ltd. (n.d.). Hempcrete Australia. Retrieved from http://www.hempcrete.com.au/

JSCE-SF4. (1984). JSCE-SF4. Method of tests for flexural strength and flexural toughness of steel fiber reinforced concrete. JSCE Japan Soci. Civil Eng, $3,58-61$.

Juárez-Alvarado, C. A., Villarreal, R. R., \& Rechy-de-Von-Roth, M. de los Á. (2004). Uso de fibras naturales de lechuguilla como refuerzo en concreto. Ingenierías, 7(22), 7-19.

Li, Y., Mai, Y., \& Ye, L. (2006). Sisal fibre and its composites : a review of recent developments. Composites Science and Technology, 60(2000), 20372055.

Ministerio de Fomento. Comisión Permanente del Hormigón. (2008). EHE-08. Instrucción de Hormigón Estructural. Madrid: Centro de Publicaciones Secretaría General Técnica Ministerio de OFmento.

Paiva, M., Ammar, I., Campos, A, Cheikh, R., \& Cunha, A. (2007). Alfa fibres: Mechanical, morphological and interfacial characterization. Composites Science and Technology, 67(6), 1132-1138. https://doi.org/10.1016/j.compscitech.2006.05.019

Pereira de Oliveira, L. A., \& Castro-Gomes, J. P. (2011). Physical and mechanical behaviour of recycled PET fibre reinforced mortar. Construction and Building Materials, 25(4), 1712-1717. https://doi.org/10.1016/j.conbuildmat.2010.11.044

Ramakrishna, G., \& Sundararajan, T. (2005). Studies on the durability of natural fibres and the effect of corroded fibres on the strength of mortar. Cement \& Concrete Composite, 27, 575-582. https://doi.org/10.1016/j.cemconcomp.2004.09.008 
Toledo Filho, R. D., Ghavami, K., Sanjuán, M. A., \& England, G. L. (2005). Free, restrained and drying shrinkage of cement mortar composites reinforced with vegetable fibres. Cement and Concrete Composites, 27(5), 537-546. https://doi.org/10.1016/j.cemconcomp.2004.09.005

Toledo Filho, R. D., Scrivener, K., England, G. L., \& Ghavami, K. (2000). Durability of alkali-sensitive sisal and coconut fibres in cement mortar composites. Cement \& Concrete Composites, 22, 127-143. 